\title{
The relationship between sclerostin and carotid artery atherosclerosis in patients with stage 3-5 chronic kidney disease
}

\author{
Ban Zhao ${ }^{1} \cdot$ Aiqun Chen ${ }^{1} \cdot$ Haitao Wang ${ }^{1} \cdot$ Ju Cui $^{2} \cdot$ Ying Sun $^{1} \cdot$ Lengnan $\mathrm{Xu}^{1} \cdot$ Yonghui Mao $^{1}$ (D)
}

Received: 11 December 2019 / Accepted: 2 May 2020 / Published online: 26 May 2020

(c) The Author(s) 2020

\begin{abstract}
Purpose Sclerostin is an antagonist of the Wnt/ $\beta$-catenin pathway. We previously reported that sclerostin is closely related to carotid artery atherosclerosis and long-term outcome in hemodialysis patients. The present study investigated the association between sclerostin, renal function, and carotid artery atherosclerosis in non-dialysis patients with stage 3-5 chronic kidney disease (CKD 3-5ND).

Methods A total of 140 patients with CKD 3-5ND were enrolled in this cross-sectional study. The Chronic Kidney Disease Epidemiology Collaboration equation was used to calculate estimated glomerular filtration rate (eGFR). Atherosclerotic plaques in the carotid artery were detected by B-mode Doppler ultrasound. Blood samples were collected to assess serum sclerostin levels. Unconditional logistic regression analysis was used to identify risk factors for carotid atherosclerotic plaques. Results The median eGFR was $24.9 \mathrm{ml} / \mathrm{min} / 1.73 \mathrm{~m}^{2}$ (interquartile range [IQR] $10.0-40.3 \mathrm{ml} / \mathrm{min} / 1.73 \mathrm{~m}^{2}$ ) and median serum sclerostin level was $46.76 \mathrm{pmol} / \mathrm{l}$ (IQR 30.18-67.56 pmol/l). Carotid atherosclerotic plaques were detected in 104 subjects (74.3\%). There was a negative association between sclerostin level and eGFR $(r=-0.214, p=0.011)$. Unconditional logistic regression analysis revealed that sclerostin level was an independent risk factor for the occurrence of carotid plaques, with an odds ratio (95\% confidence interval) of $1.026(1.003,1.051)$.

Conclusion Serum sclerostin increases with declining renal function in patients with CKD 3-5ND. Sclerostin is an independent risk factor for carotid atherosclerosis.
\end{abstract}

Keywords Atherosclerosis $\cdot$ Chronic kidney disease $\cdot$ Renal function $\cdot$ Sclerostin $\cdot$ Wnt pathway

$\begin{array}{ll}\text { Abbreviations } \\ \text { ALP } & \text { Alkaline phosphatase } \\ \text { BMI } & \text { Body mass index } \\ \text { CKD } & \text { Chronic kidney disease }\end{array}$

Ban Zhao and Aiqun Chen are equal contributors.

Electronic supplementary material The online version of this article (https://doi.org/10.1007/s11255-020-02495-x) contains supplementary material, which is available to authorized users.

Yonghui Mao

maoyonghui0214@bjhmoh.cn; mmdn2009@163.com

1 The Department of Nephrology, Beijing Hospital, National Center of Gerontology, Institute of Geriatric Medicine, Chinese Academy of Medical Sciences, NO. 1 DaHua Road, Dong Dan, Beijing 100730, People's Republic of China

2 The Key Laboratory of Geriatrics, Beijing Institute of Geriatrics, Beijing Hospital, National Center of Gerontology, National Health Commission, Institute of Geriatric Medicine, Chinese Academy of Medical Sciences, Beijing, People's Republic of China
CKD-EPI Chronic kidney disease-epidemiology collaboration equation

CKD-MBD Chronic kidney disease-mineral bone disorder

CKD-ND Non-dialysis patients with chronic kidney disease

CVD Cardiovascular disease

DM Diabetes mellitus

eGFR Estimated glomerular filtration rate

ELISA Enzyme-linked immunosorbent assay

FGF23 Fibroblast growth factor

HD Hemodialysis

HDL-C High-density lipoprotein cholesterol

Hs-CRP High-sensitivity C-reactive protein

IDMS Isotope dilution mass spectrometry

IMT Intima-media thicknesses

iPTH Intact parathyroid hormone

LDL-C Low-density lipoprotein cholesterol

LRP6 Low-density lipoprotein receptor-related proteins 6 


$\begin{array}{ll}\text { OR } & \text { Odds ratio } \\ \text { SD } & \text { Standard deviation } \\ \text { SOST KO } & \text { Sclerostin gene knockout } \\ \text { VSMCs } & \text { Vascular smooth muscle cells } \\ \text { WT } & \text { Wild-type }\end{array}$

\section{Introduction}

Cardiovascular disease is more prevalent in patients with chronic kidney disease (CKD) than in the general population $[1,2]$. The $W n t / \beta$-catenin signaling pathway plays an important role in the pathophysiology of atherosclerosis [3-5]. The Wnt- $\beta$-catenin signaling pathway is an important player in bone remodeling, and is involved in osteoblast proliferation, differentiation and bone formation [6, 7]. Dysregulation of the Wnt- $\beta$-catenin pathway also plays a crucial role in chronic kidney disease-mineral bone disorder (CKD-MBD) [6]. Sclerostin encoded by the SOST gene is an antagonist of the Wnt/B-catenin pathway that is mainly secreted by osteoblasts and inhibits bone formation [6]. Inactivating mutations in the SOST gene in mice were shown to increase bone mass [8], whereas activating mutations resulted in bone loss [9]. Monoclonal antibodies against sclerostin have been used to treat osteoporosis in postmenopausal women, resulting in a dosedependent increase in bone mineral density [10]. Serum levels of sclerostin are higher in CKD patients than in the general population and begin increasing during stage 3 [11]. However, it remains unclear how increased sclerostin relates to abnormalities in bone turnover in CKD patients.

Sclerostin has been detected on the surface of mineralized osteoblast-like cells in vitro and in the calcified aortic valve tissue of patients undergoing hemodialysis (HD) [12, 13], as well as in carotid atherosclerotic plaques by immunohistochemistry [14]. Clinical studies have reported a correlation between serum sclerostin levels and atherosclerosis in obese and diabetic patients $[15,16]$. Based on this evidence, we hypothesized that sclerostin plays an important role in the pathophysiology of atherosclerosis. Few studies have examined the correlation between serum sclerostin level and atherosclerosis in non-dialysis patients with CKD (CKDND) [17]. Here we investigated the relationship between sclerostin and atherosclerosis in non-dialysis patients with stage 3-5 CKD (CKD 3-5ND).

\section{Methods}

\section{Study population}

A total of 140 patients aged $\geq 18$ years with CKD 3-5ND were enrolled in the study between February 2015 and October 2016. Patients on systemic immunosuppressive medication or with active cancer or liver disease, malignant hematologic disorders, acute renal failure, fractures, and/or acute or chronic infections were excluded.

The detailed medical history including age, sex, height, weight, and cause of CKD (chronic glomerulonephritis, hypertensive renal disease, diabetic nephropathy, chronic interstitial nephritis, polycystic kidney disease, autoimmune disease, or other disease) were recorded. We also obtained information related to medical history, smoking (patients who had stopped smoking for $>5$ years were classified as non-smokers), diabetes mellitus (DM), and hypertension (including primary and renal hypertension). The study protocol was approved by the ethics committee of Beijing Hospital (no. 2014BJYYEC-058-01), and written informed consent was obtained from all patients.

\section{Assessment of kidney function}

Estimated glomerular filtration rate (eGFR) was calculated using the Chronic Kidney Disease Epidemiology Collaboration equation, as shown below:

$$
\begin{aligned}
\mathrm{eGFR}= & 175 \times[\text { serum creatinine }]^{-1.154} \\
& \times \operatorname{age}^{-0.203}(\times 0.742, \text { if female }) .
\end{aligned}
$$

The eGFR data were used to group patients according to CKD stage as follows: stage 3 (eGFR: $30-60 \mathrm{ml} /$ $\mathrm{min} / 1.73 \mathrm{~m}^{2}$ ), stage 4 (eGFR: $15-30 \mathrm{ml} / \mathrm{min} / 1.73 \mathrm{~m}^{2}$ ), and stage 5 (eGFR: $<15 \mathrm{ml} / \mathrm{min} / 1.73 \mathrm{~m}^{2}$ ).

\section{Biochemical analyses}

Venous blood samples were collected in a fasting state, and serum creatinine levels were measured with the enzymatic isotope dilution mass spectrometry traceable standardized method (Cobas C501 Biochemical Analyzer; Roche Diagnostics, Mannheim, Germany). Serum levels of uric acid, total serum calcium, phosphate, albumin, total cholesterol, low-density lipoprotein cholesterol (LDL-C), high-density lipoprotein cholesterol (HDL-C), alkaline phosphatase (ALP), high-sensitivity C-reactive protein (hs-CRP), intact parathyroid hormone (iPTH), and hemoglobin were measured according to standard methods at the hospital's central laboratory. Serum samples were then stored at $-80^{\circ} \mathrm{C}$, an enzyme-linked immunosorbent assay kit (Biomedica, Wien, Austria) was used to determine serum levels of sclerostin at October 2016. A total of 18 patients with normal renal function (11 male, seven females; mean age, 59.9 years) were recruited for the control group; the median sclerostin level in these subjects was $36.31(26.29,43.60) \mathrm{pmol} / 1$. Baseline serum samples of the 140 patients were stored at $-80{ }^{\circ} \mathrm{C}$, the levels of 25 hydroxyvitamin D were tested in March 
2020 (Cobas e601 automatic electrochemiluminescence analyzer, Roche Diagnostics, Mannheim, Germany).

\section{B mode and Doppler ultrasound imaging of common carotid artery}

Baseline B mode and Doppler ultrasound images of the common carotid artery were obtained. An atherosclerotic plaque was defined as a focal structure encroaching into the arterial lumen by at least $0.5 \mathrm{~mm}$ or $50 \%$ of the surrounding intimamedia thickness value, or with a thickness $>1.5 \mathrm{~mm}$, as measured from the media-adventitia interface to the intimalumen interface [18]. The sonographer searched for plaques by scanning the common carotid artery and its bifurcation, proximal internal carotid artery, and external carotid artery segment in both longitudinal and cross-sectional planes [19]. Bilateral carotid arteries were analyzed by color Doppler ultrasound at a frequency of $5-10 \mathrm{MHz}$ (Model IU-22; Philips, Amsterdam, The Netherlands) by an experienced sonographer, with each measurement repeated twice.

\section{Statistical analyses}

Statistical analyses were performed with SPSS v20.0 software (IBM, Armonk, NY, USA). The normality of raw data was assessed with the Kolmogorov-Smirnov test. Normally and non-normally distributed continuous variables are expressed as mean \pm standard deviation and median with 25th and 75th percentiles, respectively. Differences between groups were evaluated with the Student's $t$ test or the Mann-Whitney $U$ test depending on whether the data were normally distributed. Categorical data are reported as percentages and were assessed with the chi-squared test. Spearman's method was used to analyze the correlation between sclerostin level and other parameters. Risk factors for carotid atherosclerotic plaques were evaluated by unconditional logistic regression. For all analyses, $p<0.05$ was considered as statistically significant.

\section{Results}

\section{Baseline patient characteristics}

The demographic and clinical characteristics of the study population are shown in Table 1. A total of 140 subjects (age range 25-81 years) were enrolled, including 60 patients with DM (44.3\%). Among these patients, the causes of CKD were chronic glomerulonephritis $(n=41,29.3 \%)$, hypertensive renal disease $(n=39,27.9 \%)$, diabetic nephropathy ( $n=33$, $23.6 \%)$, chronic interstitial nephritis $(n=15,10.7 \%)$, polycystic kidney disease $(n=3,2.1 \%)$, autoimmune diseases $(n=2,1.4 \%)$, and other diseases $(n=7,5.0 \%)$. There were
Table 1 The relationships between serum sclerostin level and renal function and bone and mineral metabolism

\begin{tabular}{lrl}
\hline Variable & \multicolumn{1}{l}{$r$} & $p$ value \\
\hline eGFR, $\mathrm{ml} / \mathrm{min} / 1.73 \mathrm{~m}^{2}$ & -0.214 & 0.011 \\
Calcium, mmol/L & -0.225 & 0.007 \\
Phosphate, $\mathrm{mmol} / \mathrm{L}$ & 0.185 & 0.028 \\
ALP, U/L & -0.150 & 0.078 \\
Intact parathyroid hormone, $\mathrm{pg} / \mathrm{mL}$ & 0.098 & 0.250 \\
25(OH) vitamin $\mathrm{D}, \mathrm{ng} / \mathrm{ml}$ & -0.075 & 0.378 \\
\hline
\end{tabular}

58 patients in CKD stage 3 (41.4\%), 36 in stage 4 (25.7\%), and 46 in stage $5(32.9 \%)$.

The median eGFR was $24.9 \mathrm{ml} / \mathrm{min} / 1.73 \mathrm{~m}^{2}$, and median serum sclerostin concentration was $46.76 \mathrm{pmol} / \mathrm{l}$. Carotid atherosclerotic plaques were detected in 104 subjects (74.3\%). Males had significantly higher serum sclerostin levels than females (57.26 vs $43.05 \mathrm{pmol} / \mathrm{l}$; median, $p<0.001$ ). Higher sclerostin levels were observed in patients with a history of smoking (59.08 vs $45.93 \mathrm{pmol} / \mathrm{l}$; median, $p=0.063$ ) and hypertension ( 47.75 vs $34.41 \mathrm{pmol} / \mathrm{l}$; median, $p=0.056$ ) compared to non-smokers and patients with no history of hypertension. Sclerostin levels were comparable between patients with and those without DM (47.28 vs $45.75 \mathrm{pmol} / \mathrm{l}$; median, $p=0.273$ ).

\section{Relationships between serum sclerostin level and renal function and bone and mineral metabolism}

Serum sclerostin levels gradually increased with the deterioration of renal function. A Spearman correlation analysis showed that serum sclerostin was negatively correlated with eGFR $(r=-0.214, p=0.011)$, and a higher level was observed in patients with stage 5 as compared to stage 3 CKD (42.53 vs $52.64 \mathrm{ng} / \mathrm{ml}$, median, $p=0.048$ ), although the levels were comparable between stages 3 and 4 (42.53 vs $44.11 \mathrm{ng} / \mathrm{ml}, p=0.741)$ and between stages 4 and 5 (44.11 vs $52.64 \mathrm{ng} / \mathrm{ml}, p=0.115$ ) (Fig. 1). Spearman correlation analysis showed that serum sclerostin was negatively correlated with calcium $(r=-0.225, p=0.007)$ but positively correlated with phosphorus $(r=0.185, p=0.028)$. There was no correlation between serum sclerostin and iPTH, hsCRP, 25(OH) vitamin D, and alkaline phosphatase (Table 1). Sclerostin level was non-normally distributed and was log transformed, and multiple stepwise regression analysis was carried out with sex, age, body mass index (BMI), eGFR, iPTH, 25(OH) vitamin D, serum calcium, phosphorus, DM, and atherosclerosis as covariates. The results showed that sex $(p=0.001)$, phosphorus $(p<0.001)$, and atherosclerosis $(p=0.001)$ were independently associated with serum sclerostin level. 


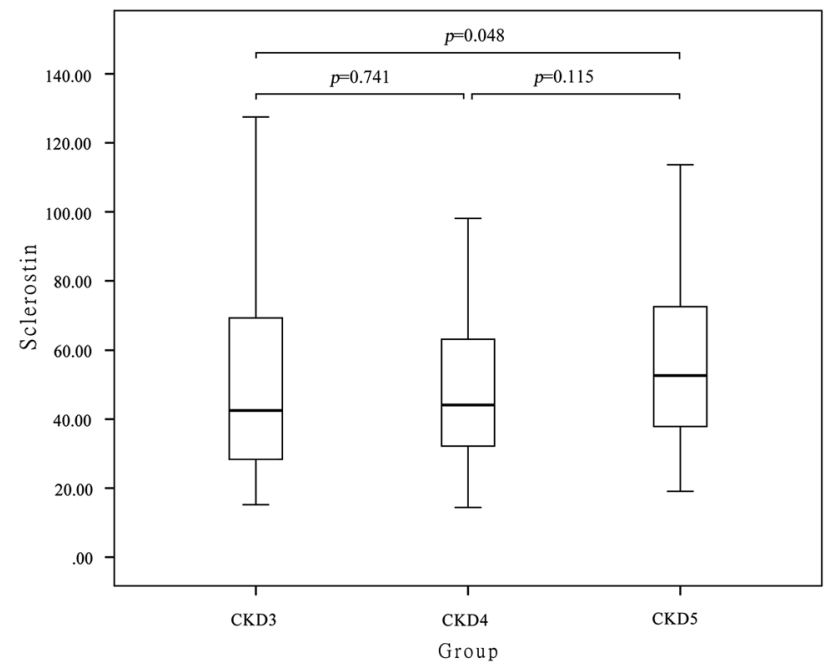

Fig. 1 Comparison of serum sclerostin between patients in CKD 3, 4 and 5 stages

\section{Comparison between high and low sclerostin groups}

The subjects $(n=140)$ were divided into high and low sclerostin groups according to median levels (46.76 pmol/l) as in previous studies. The high sclerostin group had more male patients $(p=0.002)$ and higher levels of serum phosphate $(p=0.042)$, and lower eGFR $(p=0.020)$, serum total calcium $(p=0.007)$, hemoglobin $(p=0.008)$, and ALP $(p=0.034)($ Table 2$)$.

\section{Comparison between patients with and without atherosclerotic plaques}

Subjects were divided into plaque $(n=104)$ and non-plaque $(n=36)$ groups according to the presence of carotid atherosclerotic plaques. The plaque group had higher serum levels of sclerostin $(p=0.013)$ (Fig. 2), were older $(p<0.001)$, and had a higher pulse pressure $(p=0.036)$, and higher prevalence of hypertension $(p=0.007)$ and DM $(p<0.001)$ compared to the non-plaque group. Meanwhile, the proportion of patients taking statins was higher in the plaque group (70.2 vs. $36.1 \%, p<0.001$ ) (Table 3 ).

\section{Factors related to carotid atherosclerotic plaques}

Unconditional logistic regression analysis was used to identify factors related to carotid atherosclerotic plaques. Age, BMI, DM, hypertension, pulse pressure, eGFR, and sclerostin $(p<0.05)$ were independent variables and the presence of carotid atherosclerotic plaques was the dependent variable. The results showed that age, BMI, DM, and sclerostin were independent factors that were significantly related to the presence of carotid plaques, with odds ratios (95\% confidence interval) of $1.136(1.082,1.192), 1.170$ (1.000, 1.369), $3.372(1.020,11.142)$, and $1.026(1.003,1.051)$, respectively (Table 4).

\section{Discussion}

The results of this study indicate that serum sclerostin level is inversely related to renal function, and reveal an association between serum sclerostin level and carotid plaques in patients with CKD 3-5ND. Although sclerostin level has been shown to increase with declining renal function [11, 20], the mechanistic basis for elevated serum sclerostin levels in CKD patients has not been elucidated. It was reported that urinary sclerostin excretion increases with decreasing eGFR, while higher sclerostin levels in CKD patients were unrelated to a decline in renal function [21]. CKD patients have a higher percentage of sclerostin-positive osteocytes than healthy subjects (38\% and $26 \%$ in stage $2-3$ and stage $4 \mathrm{CKD}$, respectively, vs $5.3 \%$ in the control group), which may be due in part to increased sclerostin production by osteocytes [22]. An immunohistochemical analysis showed that serum sclerostin level in calcified aortic valves of HD patients was closely associated with vessel calcification, suggesting that sclerostin maybe originates from an extraskeletal source [13].

Atherosclerotic plaque formation is a complex process that involves vascular calcification, inflammation, endothelial dysfunction, and the proliferation and migration of vascular smooth muscle cells (VSMCs) [3]. Wnt- $\beta$-catenin signaling plays an important role in the pathophysiology of atherosclerosis and regulates endothelial inflammation [23], mesenchymal stem cell differentiation [24, 25], and the proliferation, migration and survival of VSMCs [4]. Wnt protein is also known to promote the adhesion of monocytes to endothelial cells [26]. Missense mutations in the Wnt receptor LDL receptor-related protein 6 have been linked to an increased incidence of early-onset coronary artery disease, hypertension, high-serum LDL, and DM [27]. Sclerotin is a soluble antagonist of the Wnt- $\beta$-catenin pathway that disrupts signal transduction by blocking the binding of Wnt ligand to the transmembrane receptor complex [6]. Sclerostin levels were found to be elevated in the media relative to the intima of blood vessels and in vascular smooth muscle cells compared to infiltrating macrophages [14]. Sclerostin may maintain aortic homeostasis by inhibiting inflammation and degradation of the extracellular matrix [28]; moreover, both the transgenic introduction of human sclerostin, and the administration of recombinant mouse sclerostin into apolipoprotein E-deficient mice inhibited angiotensin IIinduced aneurysm formation and atherosclerosis [28]. In the present study, sclerostin was independently associated 
Table 2 Demographic and clinical characteristics of the patients involved in this study along with comparisons between patients in the high and low sclerostin groups

\begin{tabular}{|c|c|c|c|c|}
\hline Variable & All patients $n=140$ & $\begin{array}{l}\text { Sclerostin }<46.76 \mathrm{pmol} / \mathrm{L} \\
n=70\end{array}$ & $\begin{array}{l}\text { Sclerostin }>46.76 \mathrm{pmol} / \mathrm{L} \\
n=70\end{array}$ & $p$ value \\
\hline Age (years) & $64(51,73)$ & $64(49,74)$ & $64(52,73)$ & 0.995 \\
\hline Male, $n(\%)$ & $72(51.4)$ & $27(38.6)$ & $45(64.3)$ & 0.002 \\
\hline Diabetes, $n(\%)$ & $60(44.3)$ & $29(41.4)$ & $31(44.3)$ & 0.733 \\
\hline Hypertension, $n(\%)$ & $120(85.7)$ & $57(81.4)$ & $63(90.0)$ & 0.147 \\
\hline Atherosclerotic plaque, $n(\%)$ & $104(74.3)$ & $50(71.4)$ & $54(77.1)$ & 0.439 \\
\hline Smoker, $n(\%)$ & $38(27.1)$ & $16(22.9)$ & $22(31.4)$ & 0.254 \\
\hline $\operatorname{BMI}\left(\mathrm{kg} / \mathrm{m}^{2}\right)$ & $24.82 \pm 3.91$ & $25.00 \pm 3.46$ & $24.65 \pm 4.33$ & 0.601 \\
\hline Systolic BP (mmHg) & $130(130,150)$ & $133(130,150)$ & $130(130,150)$ & 0.594 \\
\hline Diastolic BP (mmHg) & $80(70,86)$ & $80(70,90)$ & $80(70,80)$ & 0.266 \\
\hline Pulse pressure (mmHg) & $60(50,70)$ & $60(50,65)$ & $60(50,70)$ & 0.431 \\
\hline eGFR $\left(\mathrm{mL} / \mathrm{min} / 1.73 \mathrm{~m}^{2}\right)$ & $24.9(10.0,40.3)$ & $26.8(14.3,44.3)$ & $22.0(8.0,36.8)$ & 0.020 \\
\hline Hemoglobin $(\mathrm{g} / \mathrm{L})$ & $110 \pm 25$ & $115 \pm 23$ & $104 \pm 26$ & 0.008 \\
\hline Albumin $(\mathrm{g} / \mathrm{L})$ & $40(37,43)$ & $41(38,43)$ & $40(36,42)$ & 0.050 \\
\hline Phosphate (mmol/L) & $1.37(1.17,1.68)$ & $1.32(1.18,1.52)$ & $1.45(1.16,1.82)$ & 0.042 \\
\hline iPTH (pg/mL) & $85(47,189)$ & $79(45,179)$ & $103(50,207)$ & 0.161 \\
\hline $25(\mathrm{OH})$ vitamin $\mathrm{D}(\mathrm{ng} / \mathrm{ml})$ & $8.3(4.6,12.0)$ & $9.6(5.5,13.2)$ & $7.2(4.2,11.7)$ & 0.141 \\
\hline Alkaline phosphatase (U/L) & $75(59,92)$ & $81(59,97)$ & $67(59,83)$ & 0.034 \\
\hline Calcium (mmol/L) & $2.23(2.10,2.34)$ & $2.28(2.16,2.34)$ & $2.18(2.00,2.32)$ & 0.007 \\
\hline Uric acid (umol/L) & $442 \pm 126$ & $424 \pm 117$ & $460 \pm 133$ & 0.086 \\
\hline Cholesterol (mmol/L) & $4.31 \pm 0.95$ & $4.37 \pm 0.98$ & $4.25 \pm 0.93$ & 0.429 \\
\hline LDL-C (mmol/L) & $2.54 \pm 0.75$ & $2.56 \pm 0.71$ & $2.52 \pm 0.78$ & 0.738 \\
\hline HDL-C (mmol/L) & $1.08(0.91,1.28)$ & $1.13(0.91,1.35)$ & $1.07(0.91,1.25)$ & 0.528 \\
\hline hs-CRP (mg/dl) & $1.84(0.85,4.67)$ & $1.84(0.61,4.13)$ & $1.82(0.86,6.94)$ & 0.250 \\
\hline Anti-hypertensive drug, $n(\%)$ & $136(97.1)$ & $68(97.1)$ & $68(97.1)$ & 1.000 \\
\hline Statin, $n(\%)$ & $86(61.4)$ & $48(68.6)$ & $38(54.3)$ & 0.083 \\
\hline Calcium-based phosphate binders, $n(\%)$ & $28(20.0)$ & $15(21.4)$ & $13(18.6)$ & 0.673 \\
\hline Calcitriol, $n(\%)$ & $43(30.7)$ & $27(38.6)$ & $16(22.8)$ & 0.044 \\
\hline
\end{tabular}

Normally distributed variables are shown as mean \pm standard deviation; non-normally distributed variables are shown as medians (with 25 and $75 \%$ interquartile ranges in parentheses)

$B M I$ body mass index, $e G F R$ estimated glomerular filtration rate, $i P T H$ intact parathyroid hormone, $L D L-C$ low-density lipoprotein cholesterol, $H D L-C$ high-density lipoprotein cholesterol, $h s-C R P$ high-sensitivity C-reactive protein

with atherosclerotic plaques, which is consistent with observations in HD patients $[29,30]$. Thus, sclerostin may play an important role in the process of atherosclerosis. We speculate that the elevated sclerostin may partly originate from atherosclerotic plaques in CKD patients, which suppresses atherosclerosis in a negative feedback mechanism by inhibiting Wnt signaling, thereby protecting against plaque development. Further studies are needed to determine the precise contributions of sclerostin and the Wnt- $\beta$-catenin axis to atherosclerosis.

iPTH inhibits sclerostin expression in osteocytes. Evidence from patients with DM and primary hyperparathyroidism has revealed a negative relationship between serum iPTH and sclerostin levels [31]. Clinical studies have yielded inconclusive findings regarding the relationship between circulating sclerostin levels and $\mathrm{PTH}$ in
CKD patients. In dialysis patients, sclerostin was negatively correlated with iPTH $[32,33]$, which may be related to the suppression of sclerostin production by osteocytes, or the decrease of bone mass in secondary hyperparathyroidism [32]. However, we did not observe a correlation between iPTH and sclerostin in CKD patients prior to dialysis, in agreement with previous reports $[11,20]$. It is possible that any suppressive effect by iPTH was masked by its low levels in early-stage CKD and elderly CKD patients. In cases of advanced CKD, sclerostin and iPTH levels are elevated and osteocytes may become resistant to the suppressive effects of the latter. Moreover, other factors such as phosphorus and fibroblast growth factor 23 directly or indirectly regulate sclerostin in CKD [34, 35]. It is also possible that sclerostin is upregulated by as-yet unknown factors under uremic conditions. 


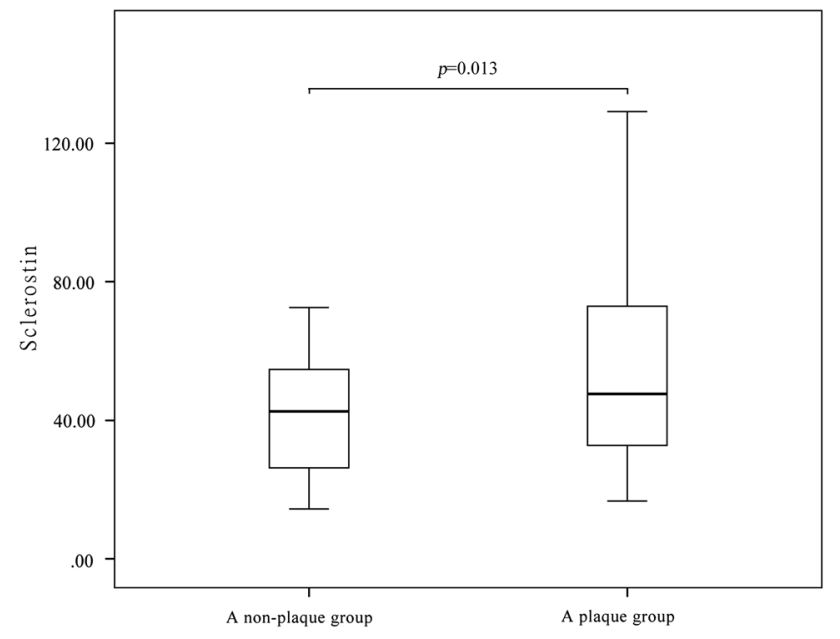

Fig. 2 Comparison of serum sclerostin between patients in the plaque group and the non-plaque group
It was shown that sclerostin has a direct influence on mineral metabolism, compared to wild-type mice (WT mice), urinary excretion of calcium and the fractional excretion of calcium were decreased in sclerostin knockout mice (sost KO mice) [36]. Furthermore, in the sost KO mice, the serum concentrations of intact FGF-23 were significantly decreased, and the concentrations of the $1-\alpha, 25(\mathrm{OH})_{2} \mathrm{D}$ were increased [36]. In a mouse model of CKD, 1- $\alpha$, $25(\mathrm{OH})_{2} \mathrm{D}$ production in osteocytes was shown to stimulate sclerostin and inhibit BMP2 production [37]. Barbara et al. has found plasma sclerostin concentration positively correlated with serum 25-OH-Vitamin D in hemodialysis patients [32]. However, we have found no correlation between serum sclerostin and 25-OH-Vitamin D in the present study. In a model of CKD with adynamic osteopathy, increased bone expression and blood level of sclerostin were closely related to dietary phosphorus intake [38]. In a clinical study of HD patients, a positive correlation was observed between serum sclerostin and phosphorus levels, and phosphorus was an

Table 3 Comparisons between patients with and without atherosclerotic plaques

\begin{tabular}{|c|c|c|c|}
\hline Variable & Patients with plaques $n=104$ & Patients without plaques $n=36$ & $p$ value \\
\hline Age (years) & $67.0(61.0,74.0)$ & $44.5(35.3,55.3)$ & $<0.001$ \\
\hline Male, $n(\%)$ & $58(55.8)$ & $14(38.9)$ & 0.081 \\
\hline Diabetes, $n(\%)$ & $54(51.9)$ & $6(16.7)$ & $<0.001$ \\
\hline Hypertension, $n(\%)$ & $94(90.4)$ & $26(72.2)$ & 0.007 \\
\hline Smoker, $n(\%)$ & $32(30.8)$ & $6(16.7)$ & 0.101 \\
\hline $\mathrm{BMI}\left(\mathrm{kg} / \mathrm{m}^{2}\right)$ & $25.35 \pm 3.72$ & $23.31 \pm 4.11$ & 0.007 \\
\hline Systolic BP (mmHg) & $130(130,150)$ & $137(130,150)$ & 0.896 \\
\hline Pulse pressure (mmHg) & $60(50,70)$ & $50(45,60)$ & 0.036 \\
\hline $\mathrm{eGFR}\left(\mathrm{mL} / \mathrm{min} / 1.73 \mathrm{~m}^{2}\right)$ & $11.8(27.0,40.7)$ & $5.6(18.3,38.0)$ & 0.069 \\
\hline Hemoglobin $(\mathrm{g} / \mathrm{L})$ & $113 \pm 23$ & $101 \pm 27$ & 0.013 \\
\hline Albumin $(\mathrm{g} / \mathrm{L})$ & $41(38,43)$ & $40(37,43)$ & 0.517 \\
\hline Phosphate (mmol/L) & $1.37(1.11,1.60)$ & $1.39(1.19,1.92)$ & 0.107 \\
\hline iPTH (pg/mL) & $77.9(46.0,172.3)$ & $114.5(58.0,243.8)$ & 0.037 \\
\hline $25(\mathrm{OH})$ vitamin $\mathrm{D}(\mathrm{ng} / \mathrm{ml})$ & $9.3(4.6,13.6)$ & $7.2(4.8,10.4)$ & 0.134 \\
\hline Alkaline phosphatase (U/L) & $75(59,93)$ & $74(57,91)$ & 0.543 \\
\hline Calcium (mmol/L) & $2.26(2.13,2.34)$ & $2.17(1.97,2.33)$ & 0.144 \\
\hline Uric acid (umol/L) & $418.8 \pm 107.3$ & $509.7 \pm 150.8$ & 0.002 \\
\hline Cholesterol (mmol/L) & $4.26 \pm 0.94$ & $4.46 \pm 0.99$ & 0.265 \\
\hline LDL-C (mmol/L) & $2.51 \pm 0.75$ & $2.64 \pm 0.75$ & 0.379 \\
\hline $\mathrm{HDL}-\mathrm{C}(\mathrm{mmol} / \mathrm{L})$ & $1.07(0.92,1.28)$ & $1.13(0.89,1.35)$ & 0.894 \\
\hline hs-CRP (mg/dl) & $1.80(0.83,5.07)$ & $2.02(1.20,3.73)$ & 0.635 \\
\hline Sclerostin (pmol/L) & $47.66(32.60,72.91)$ & $42.62(26.20-55.50)$ & 0.013 \\
\hline Anti-hypertensive drug, $n(\%)$ & $100(96.2)$ & $36(100.0)$ & 0.233 \\
\hline Statin, $n(\%)$ & $73(70.2)$ & $13(36.1)$ & $<0.001$ \\
\hline Calcium-based phosphate binders, $n(\%)$ & $20(19.2)$ & $8(22.2)$ & 0.699 \\
\hline Calcitriol, $n(\%)$ & $33(31.7)$ & $10(27.8)$ & 0.658 \\
\hline
\end{tabular}

Normally distributed variables are shown as mean \pm standard deviation; non-normally distributed variables are shown as medians (with 25 and $75 \%$ interquartile ranges in parentheses)

$B M I$ body mass index, $e G F R$ estimated glomerular filtration rate, $i P T H$ intact parathyroid hormone, $L D L-C$ low-density lipoprotein cholesterol, $H D L-C$ high-density lipoprotein cholesterol, $h s-C R P$ high-sensitivity $\mathrm{C}$-reactive protein 
Table 4 Factors related to carotid atherosclerotic plaques

\begin{tabular}{llrl}
\hline Variable & $\begin{array}{l}\text { Coef- } \\
\text { ficient }(r) \\
\text { or } \beta\end{array}$ & $p$ & OR (OR 95\% CI) \\
\hline Age (per year) & 0.127 & $<0.001$ & $1.136(1.082,1.192)$ \\
BMI $\left(\mathrm{kg} / \mathrm{m}^{2}\right)$ & 0.157 & 0.049 & $1.170(1.000,1.369)$ \\
Diabetes $(\mathrm{Y}$ versus N) & 1.125 & 0.046 & $3.372(1.020,11.142)$ \\
Sclerostin $(1 \mathrm{pmol} / \mathrm{L})$ & 0.026 & 0.029 & $1.026(1.003,1.051)$ \\
\hline
\end{tabular}

$B M I$ body mass index, $O R$ odds ratios, $C I$ confidence interval

independent factor affecting the level of sclerostin [32], which was also supported by our data. However, the regulatory relationship between calcium, phosphorus, vitamin D, and sclerostin remains to be determined.

This study had several limitations. First, this was a crosssectional study with a relatively small sample size and we did not find clear evidence of a causal relationship between sclerostin and atherosclerosis. Second, the study involved only a single center in China, which limits the generalizability of the findings to other ethnic groups with different atherosclerosis risk profiles. Finally, we lacked histopathologic data from atherosclerotic plaques that could provide insight into the degree to which sclerostin affects plaque formation.

\section{Conclusion}

In conclusion, the results presented here indicate that sclerostin level increases with the deterioration of renal function in patients with CKD 3-5ND, and that sclerostin plays a critical role in the development of atherosclerosis. Sclerostin is an independent risk factor for carotid atherosclerosis.

Author contributions $\mathrm{BZ}$ designed the experiments, performed the experiments, collected the data, performed the formal analysis and wrote the manuscript. AC designed the experiments, performed the experiments, collected the data, performed the formal analysis. HW, JC, YS and LX performed the experiments and collected the data. YM designed the experiments and reviewed/edited the manuscript.

Funding This study was supported by the Ministry of Science and Technology of the People's Republic of China (No. 2017ZX09304026). The funding body had no role in study design, data collection, data interpretation, or manuscript writing.

\section{Compliance with ethical standards}

Conflict of interest The authors declare that they have no competing interests.

Ethical approval The study was performed in accordance with the Declaration of Helsinki and was approved by the local ethics committee of Beijing Hospital (Ethical approval number: 2014BJYYEC-058-01).
Informed consent Written informed consent was obtained from all patients.

Open Access This article is licensed under a Creative Commons Attribution 4.0 International License, which permits use, sharing, adaptation, distribution and reproduction in any medium or format, as long as you give appropriate credit to the original author(s) and the source, provide a link to the Creative Commons licence, and indicate if changes were made. The images or other third party material in this article are included in the article's Creative Commons licence, unless indicated otherwise in a credit line to the material. If material is not included in the article's Creative Commons licence and your intended use is not permitted by statutory regulation or exceeds the permitted use, you will need to obtain permission directly from the copyright holder. To view a copy of this licence, visit http://creativecommons.org/licenses/by/4.0/.

\section{References}

1. Moody WE, Edwards NC, Chue CD, Ferro CJ, Townend JN (2013) Arterial disease in chronic kidney disease. Heart 99:365-372

2. Mafham M, Emberson J, Landray MJ, Wen CP, Baigent C (2011) Estimated glomerular filtration rate and the risk of major vascular events and all-cause mortality: a meta-analysis. PLoS ONE 6:e25920

3. Marinou K, Christodoulides C, Antoniades C, Koutsilieris M (2012) Wnt signaling in cardiovascular physiology. Trends Endocrinol Metab 23:628-636

4. Mill C, George SJ (2012) Wnt signalling in smooth muscle cells and its role in cardiovascular disorders. Cardiovasc Res 95:233-240

5. Dejana E (2010) The role of wnt signaling in physiological and pathological angiogenesis. Circ Res 107:943-952

6. Brandenburg VM, D'Haese P, Deck A et al (2016) From skeletal to cardiovascular disease in 12 steps-the evolution of sclerostin as a major player in CKD-MBD. Pediatr Nephrol 31:195-206

7. Monroe DG, McGee-Lawrence ME, Oursler MJ, Westendorf JJ (2012) Update on Wnt signaling in bone cell biology and bone disease. Gene 492:1-18

8. Li X, Ominsky MS, Niu QT et al (2008) Targeted deletion of the sclerostin gene in mice results in increased bone formation and bone strength. J Bone Miner Res 23:860-869

9. Winkler DG, Sutherland MK, Geoghegan JC et al (2003) Osteocyte control of bone formation via sclerostin, a novel BMP antagonist. EMBO J 22:6267-6276

10. McClung MR, Grauer A, Boonen S et al (2014) Romosozumab in postmenopausal women with low bone mineral density. N Engl J Med 370:412-420

11. Pelletier S, Dubourg L, Carlier MC, Hadj-Aissa A, Fouque D (2013) The relation between renal function and serum sclerostin in adult patients with CKD. Clin J Am Soc Nephrol 8:819-823

12. Zhu D, Mackenzie NC, Millan JL, Farquharson C, MacRae VE (2011) The appearance and modulation of osteocyte marker expression during calcification of vascular smooth muscle cells. PLoS ONE 6:e19595

13. Brandenburg VM, Kramann R, Koos R et al (2013) Relationship between sclerostin and cardiovascular calcification in hemodialysis patients: a cross-sectional study. BMC Nephrol 14:219

14. Leto G, D'Onofrio L, Lucantoni F et al (2019) Sclerostin is expressed in the atherosclerotic plaques of patients who undergoing carotid endarterectomy. Diabetes Metab Res Rev 35:e3069 
15. Saadeldin MK, Elshaer SS, Emara IA, Maged M, Abdel-Aziz AK (2018) Serum sclerostin and irisin as predictive markers for atherosclerosis in Egyptian type II diabetic female patients: a case control study. PLoS ONE 13:e0206761

16. Popovic DS, Mitrovic M, Tomic-Naglic D et al (2017) The Wnt/ beta-catenin signalling pathway inhibitor sclerostin is a biomarker for early atherosclerosis in obesity. Curr Neurovasc Res 14:200-206

17. Figurek A, Spasovski G (2018) Is serum sclerostin a marker of atherosclerosis in patients with chronic kidney disease-mineral and bone disorder? Int Urol Nephrol 50:1863-1870

18. Touboul PJ, Hennerici MG, Meairs S et al (2004) Mannheim intima-media thickness consensus. Cerebrovasc Dis 18:346-349

19. Touboul PJ, Hernández-Hernández R, Küçükoğlu S et al (2007) Carotid artery intima media thickness, plaque and framingham cardiovascular score in Asia, Africa/Middle East and Latin America: the PARC-AALA study. Int J Cardiovasc Imaging 23:557-567

20. Morena M, Jaussent I, Dupuy AM et al (2015) Osteoprotegerin and sclerostin in chronic kidney disease prior to dialysis: potential partners in vascular calcifications. Nephrol Dial Transplant 30:1345-1356

21. Cejka D, Marculescu R, Kozakowski N et al (2014) Renal elimination of sclerostin increases with declining kidney function. J Clin Endocrinol Metab 99:248-255

22. Graciolli FG, Neves KR, Barreto F et al (2017) The complexity of chronic kidney disease-mineral and bone disorder across stages of chronic kidney disease. Kidney Int 91:1436-1446

23. Kim J, Kim J, Kim DW et al (2010) Wnt5a induces endothelial inflammation via beta-catenin-independent signaling. J Immunol 185:1274-1282

24. Abedin M, Tintut Y, Demer LL (2004) Vascular calcification: mechanisms and clinical ramifications. Arterioscler Thromb Vasc Biol 24:1161-1170

25. Abedin M, Tintut Y, Demer LL (2004) Mesenchymal stem cells and the artery wall. Circ Res 95:671-676

26. Lee DK, Nathan Grantham R, Trachte AL, Trachte AL, Mannion JD, Wilson CL (2006) Activation of the canonical Wnt/betacatenin pathway enhances monocyte adhesion to endothelial cells. Biochem Biophys Res Commun 347:109-116

27. Mani A, Radhakrishnan J, Wang H et al (2007) LRP6 mutation in a family with early coronary disease and metabolic risk factors. Science 315:1278-1282

28. Krishna SM, Seto SW, Jose RJ et al (2017) Wnt signaling pathway inhibitor sclerostin inhibits angiotensin II-induced aortic aneurysm and atherosclerosis. Arterioscler Thromb Vasc Biol 37:553-566

29. Chen A, Sun Y, Cui J et al (2018) Associations of sclerostin with carotid artery atherosclerosis and all-cause mortality in Chinese patients undergoing maintenance hemodialysis. BMC Nephrol 19:264

30. Kirkpantur A, Balci M, Turkvatan A, Afsar B (2015) Independent association between serum sclerostin levels and carotid artery atherosclerosis in prevalent haemodialysis patients. Clin Kidney J 8:737-743

31. Drake MT, Khosla S (2017) Hormonal and systemic regulation of sclerostin. Bone 96:8-17

32. Pietrzyk B, Wyskida K, Ficek J et al (2019) Relationship between plasma levels of sclerostin, calcium-phosphate disturbances, established markers of bone turnover, and inflammation in haemodialysis patients. Int Urol Nephrol 51(3):519-526

33. Kuo TH, Lin WH, Chao JY et al (2019) Serum sclerostin levels are positively related to bone mineral density in peritoneal dialysis patients: a cross-sectional study. BMC Nephrol 20(1):266

34. Carrillo-Lopez N, Panizo S, Alonso-Montes C et al (2016) Direct inhibition of osteoblastic Wnt pathway by fibroblast growth factor 23 contributes to bone loss in chronic kidney disease. Kidney Int 90:77-89

35. Bisson SK, Ung RV, Mac-Way F (2018) Role of the Wnt/ beta-catenin pathway in renal osteodystrophy. Int $\mathrm{J}$ Endocrinol 2018:5893514

36. Ryan ZC, Ketha H, McNulty MS et al (2013) Sclerostin alters serum vitamin D metabolite and fibroblast growth facror 23 concentrations and the urinary excretion of calcium. Proc Natl Acad Sci USA 110(15):6199-6204

37. Nguyen-Yamamoto L, Tanaka KI, St-Arnaud R, Goltzman D (2019) Vitamin D-regulated osteocytic sclerostin and BMP2 modulate uremic extraskeletal calcification. JCI Insight 4(13):e126467

38. Ferreira JC, Ferrari GO, Neves KR et al (2013) Effects of dietary phosphate on adynamic bone disease in rats with chronic kidney disease-role of sclerostin? PLoS ONE 8:e79721

Publisher's Note Springer Nature remains neutral with regard to jurisdictional claims in published maps and institutional affiliations. 